\title{
Building national eco-cultural protection areas and the Xiangxi practice in Hunan Province
}

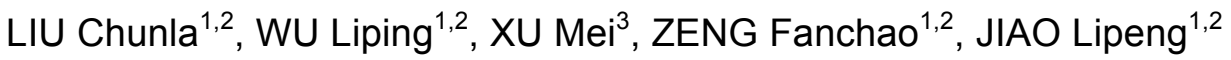 \\ 1. College of Resources and Environment Sciences, Hunan Normal University, Changsha 410081, China; \\ 2. Key Laboratory of Geospatial Big Data Mining and Application, Hunan Province, Changsha 410081, China; \\ 3. College of Tourism, Central South University of Forestry and Technology, Changsha 410004, China
}

\begin{abstract}
Since 2007, the Chinese government has initiated the building of national eco-cultural protection areas (NECPAs), thereby embarking on a significant transformation of the model of intangible cultural heritage $(\mathrm{ICH})$ protection in China. To understand the origin and outputs of this policy, this paper demonstrates the context of China's NECPAs. It proposes a conceptual NECPA framework that mainly features regional overall $\mathrm{ICH}$ protection. This is followed by an examination of the case of Xiangxi in Western Hunan as a pilot zone for China's eco-cultural protection. Xiangxi has performed much related work to promote NECPAs and made great progress in regional overall $\mathrm{ICH}$ protection. This insight suggests that there are benefits and costs associated with promotion of China's NECPAs and regional overall ICH protection. Despite the advantages of institutional innovation, the unexpected side effects actually undermine the success of plan implementation.
\end{abstract}

Keywords: national eco-cultural protection area; intangible cultural heritage; regional overall protection; Xiangxi; China

\section{Introduction}

Given China's rich and varied intangible cultural heritage (ICH), its considerable efforts in ICH protection, and the uniqueness of its protection path, China's ICH protection has attracted widespread and increasing attention from all over the world (Chen and Ye, 2014). Between 2007 and 2018, 21 national eco-cultural protection experimental areas (NECPEAs) were established in China (Figure 1), covering 17 provinces, including one autonomous region and one municipality directly under the central government, 198 counties (districts and cities), and tens of thousands of traditional cultural villages. Over the same period, 146 provincial eco-cultural protection zones with distinctive characteristics were also established in various provincial-level regions throughout the country. In December 2018, the Ministry of

Received: 2019-10-27 Accepted: 2020-04-17

Foundation: The Construction Program for First-Class Disciplines of Hunan Province, No.5010002; Education Department Research Project of Hunan Province, No.20B362

Author: Liu Chunla, PhD and Associate Professor, specialized in ecological culture geography and regional development. E-mail: liuchunla111@163.com 
Culture and Tourism of the People's Republic of China issued China's first official document on regional overall ICH protection, namely, the Management Measures for National Eco-cultural Protection Areas (NECPAs). Meanwhile, the research literature has focused on and illustrated clearly the main contents of ICH protection, including its significance, cases, and obstacles to policy implementation.

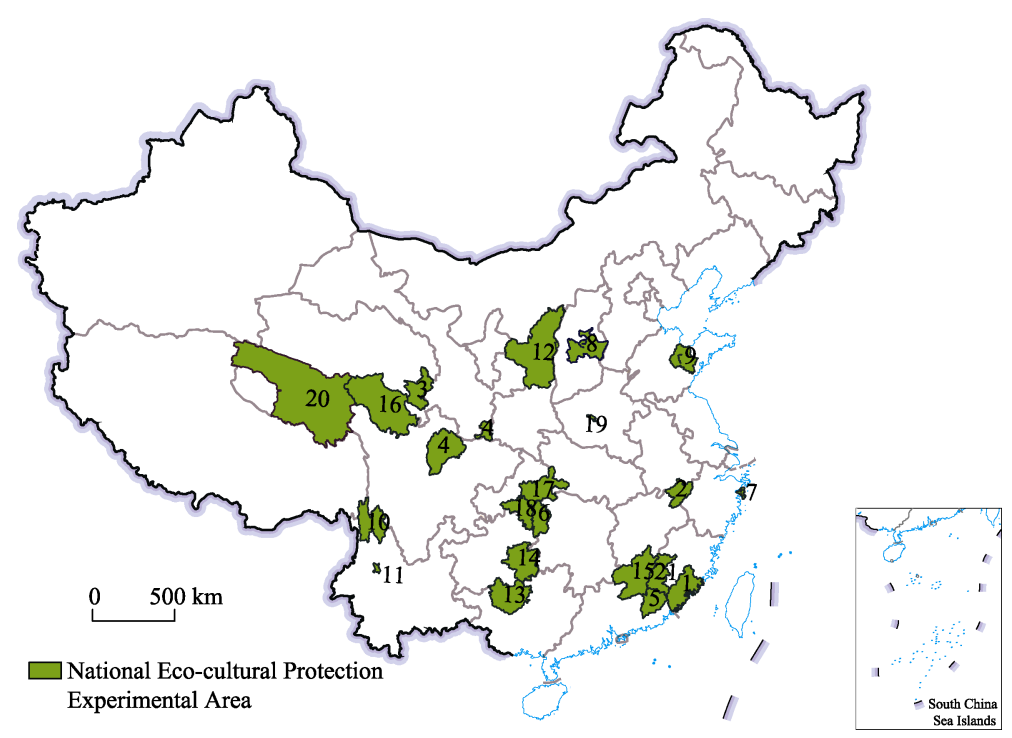

Figure 1 Distribution of 21 national eco-cultural protection experimental areas in China

Note: 1. Minnan eco-cultural protection experimental area; 2. Huizhou eco-cultural protection experimental area; 3. Regong eco-cultural protection experimental area; 4. Qiangzu eco-cultural protection experimental area; 5. Hakka (Meizhou) eco-cultural protection experimental area; 6. Wuling mountain (Xiangxi) Tujia and Miao nationalities eco-cultural protection experimental area; 7. Ocean fisheries (Xiangshan) eco-cultural protection experimental area; 8. Jinzhong eco-cultural protection experimental area; 9. Weishui eco-cultural protection experimental area; 10. Diqing eco-cultural protection experimental area; 11. Dali eco-cultural protection experimental area; 12. Shanbei eco-cultural protection experimental area; 13. Bronze drum (Hechi) eco-cultural protection experimental area; 14. Southeast Guizhou ethnic eco-cultural protection experimental area; 15. Hakka (South Jiangxi) eco-cultural protection experimental area; 16. Gesar (Guoluo) eco-cultural protection experimental area; 17. Wuling mountain (Southwest Hubei) Tujia and Miao nationalities eco-cultural protection experimental area; 18. Wuling mountain (Southeast Chongqing) Tujia and Miao nationalities eco-cultural protection experimental area; 19. Rap (Baofeng) eco-cultural protection experimental area; 20. Tibetan (Yushu) eco-cultural protection experimental area; 21. Hakka (Western Fujian) eco-cultural protection experimental area

As early as the 1980s, Greenwood (1989) pointed out that to cater to the needs of tourism development, the abuse, over-exploitation, and commercial transplantation of ICH have happened at random regardless of the characteristics of the $\mathrm{ICH}$, and that this has seriously damaged the eco-cultural condition of ICH. Based on a case study, Smith et al. (2003) proposed the role of community in the protection of ICH. Arizpe (2004) proposed that protecting ICH is to protect eco-cultural diversity and consistency. Ahmad (2006) explored the definition and scope of heritage from tangible heritage to intangible heritage. Han and Park (2009), and Harrison et al. (2010) discussed the construction of eco-museums and the design of cultural routes in the practice of $\mathrm{ICH}$ protection. Studies have also penetrated the deep-seated issues of diachronic, reflective, and advisory studies of the ICH protection system, the experience of conservation and management, the impact of ICH protection on 
local economic and social development, the relationship between ICH and human life, and the reconstruction and re-innovation of ICH protection (Long and Woods, 2011; Bille, 2012; Cominelli and Greffe, 2012; Giudici et al., 2013; Arizpe, 2015). In recent years, $\mathrm{ICH}$ protection in the process of cultural change and the evaluation and integration of heritage values in the context of cultural ecosystem services has become the focus of attention (Cozzani et al., 2017; Varnum and Grossmann, 2017; Long et al., 2018; Stanik et al., 2018; Chen et al., 2019). However, little has been written about recent progress in NECPA (An NECPEA is the trial phase of an NECPA) implementation and regional overall ICH protection.

To address these issues, the present paper examines an important case and traces the evolution of NECPEAs and regional overall ICH protection since 2006. The Xiangxi autonomous prefecture in Hunan Province of Central China was an integrated NECPEA known as the National Eco-cultural Protection Experimental Area of Tujia and Miao Nationalities in Wuling Mountain (Xiangxi). First, this paper reviews the evolution process with the emphasis on ICH protection in a series of China's policies and introduces the NECPA under policy orientation. Second, it discusses the initiatives proposed by the Chinese government, that is, the background of the publication of building NECPAs. Third, it dissects the conceptual framework of NECPAs and regional overall ICH protection. Fourth, it analyses the Xiangxi model as a typical region. Finally, it provides a macroscopic perspective to determine how the problem emerged in Xiangxi, which is an ordinary phenomenon but a prominent barrier to regional overall ICH protection in China.

\section{Understanding the context of regional overall ICH protection}

\subsection{Conceptual framework for regional overall ICH protection and NECPA construction}

ICH is a blend of cultural diversity and the guarantee of sustainable development (The "Istanbul Declaration"). The safeguarding of ICH is the universal will and common concern of mankind (The "Has Protected ICH Joint Pledge"), as well as being of universal significance. It should be carried out through bilateral, sub-regional, regional, and international cooperation, and the communities, groups, and individuals concerned should not be separated from their own ICH (Ethical Principles for the Protection of ICH).

The regional overall protection of ICH refers to respecting regional cultural diversity and complexity in a specific region, adopting effective protection measures from point to surface, and using holistic and systematic thinking to improve the ability of cultural governance, not only focusing on the productive protection and living transmission of ICH projects but also protecting the environment in which they can breed nourishment, implementing protection in a way of "seeing people, seeing things, and seeing life" (Elliott and Schmutz, 2012; Lixinski, 2013; Chen and Ye, 2014; Long, 2014). Delimiting NECPAs is an effective means for the regional overall protection of ICH areas. To preserve the national folk cultural heritage originally in the region and environment to which it belongs, so that ICH and the material cultural heritage associated with it are interdependent and closely related to peo- 
ple's production and life, besides coexisting in harmony with natural, economic, and social environment and finally making it a "living culture" (Pan, 2008; Tengberg et al., 2012; Chen et al., 2016).

An NECPA refers to a specific area approved by the central government to be established and with the protection of ICH at its core (Hudečková and Ševčíková, 2007; Del Barrio et al., 2012; Rees, 2018). It integrally protects cultural forms with rich historical and cultural accumulations, good survival status, important values, and distinct characteristics. Establishing NECPAs is conducive to the exploration of the overall protection in areas where ICH projects are concentrated and featured and in which form and connotation remain intact (Dans and González, 2018; Zhou et al., 2019). It has also been pioneering work in the regional overall protection of $\mathrm{ICH}$ in China in recent years (Figure 2).

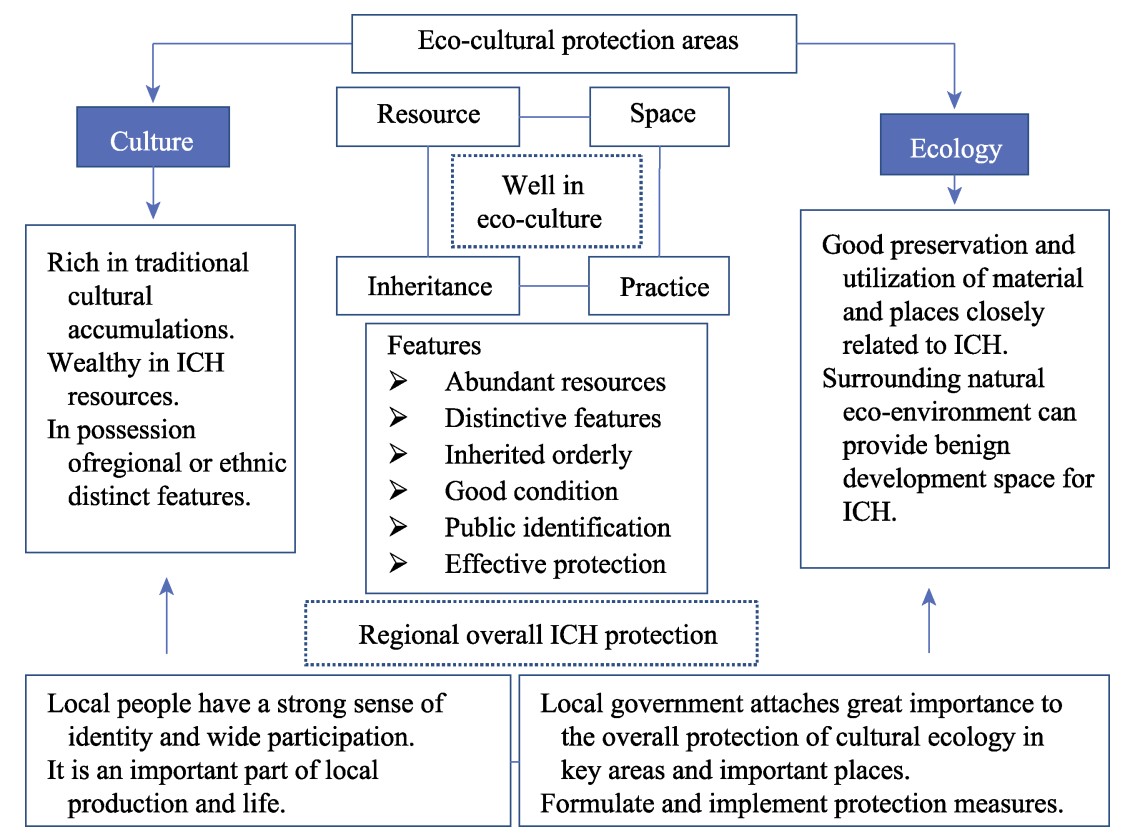

Figure 2 Conceptual framework for eco-cultural protection areas

\subsection{Evolution of China's policy orientation toward ICH protection}

China has an ancient civilization with a long history (Table 1). The Chinese nation has created a rich, colorful, and precious cultural heritage and has also always attached great importance to the protection of cultural heritage. In 2001, China submitted to the United Nations Educational, Scientific and Cultural Organization (UNESCO) the first batch of representative works of human oral and intangible heritage, at which point ICH came to public attention. The policy orientation of China is an impetus for the great shift toward ICH protection. To understand better the context of China's ICH protection, it is necessary to examine the change of $\mathrm{ICH}$ protection policies. Table 1 presents the change in policy orientation toward China's ICH protection since 2004, which directly influenced the process of ICH protection. 
Table 1 Policy orientation of China's intangible cultural heritage (ICH) protection since 2004 (Source: http:// www.ihchina.cn/index.html.)

\begin{tabular}{cl}
\hline Year & \multicolumn{1}{c}{ Major policies } \\
2004 & $\begin{array}{l}\text { Approving "Convention for the Safeguarding of the ICH"; implementing the project of protecting } \\
\text { Chinese national folk culture. }\end{array}$ \\
2005 & $\begin{array}{l}\text { Strengthening the protection of China's ICH; establishing the national ICH list assessment committee; } \\
\text { appointing the first national class of ICH representatives; conducting a census of ICH. }\end{array}$ \\
2006 & $\begin{array}{l}\text { Devising various measures for the protection and management of national ICH and the special funds; } \\
\text { establishing the national committee of experts on the protection of ICH. }\end{array}$ \\
2007 & $\begin{array}{l}\text { Publishing management measures for the marking of China's ICH; declaring "Representative Works of } \\
\text { Human ICH"; strengthening the protection of time-honored brand ICH. }\end{array}$ \\
2008 & $\begin{array}{l}\text { Formulating provisional measures for the recognition and management of representative inheritors of } \\
\text { national ICH projects. }\end{array}$ \\
2010 & $\begin{array}{l}\text { Delivering the third batch of representative successors of national ICH projects. } \\
\text { Aim to protect ICH; building NECPAs. }\end{array}$ \\
2011 & $\begin{array}{l}\text { Issuing "ICH protection law." } \\
\text { Strengthening productive protection of ICH; promulgating measures for the management of national } \\
\text { special funds for the protection of ICH. } \\
2012\end{array} \quad \begin{array}{l}\text { Publishing the list of the fourth national class of ICH representational projects. } \\
\text { Establishing "Cultural and Natural Heritage Day." } \\
\text { Implementing the project of inheritance and development of Chinese excellent traditional culture; } \\
\text { implementing the revitalization plan for Chinese traditional crafts. } \\
\text { Publishing management measures for NECPAs; supporting the establishment of ICH poverty allevia- } \\
\text { tion and employment workshops. }\end{array}$ \\
\hline
\end{tabular}

In 2004, the Standing Committee of the National People's Congress approved the "Convention for the Safeguarding of the ICH," which was adopted by the 32nd UNESCO General Conference. In the same year, the Ministry of Culture (now the Ministry of Culture and Tourism of the People's Republic of China) and the Ministry of Finance decided to carry out the project for protecting Chinese national folk culture. In 2005, the General Office of the State Council published opinions on strengthening the protection of China's ICH. At the same time, the Ministry of Culture established the National ICH List Assessment Committee, organized the appointment of the first national class of ICH representatives, and conducted a census of ICH. In 2006, measures were formulated for the protection and management of national ICH and the special funds, the National Committee of Experts on the Protection of ICH was established, and the first list of national ICH was published. Since 2007, many other major works have been done, such as printing management measures for issuing marks of China's ICH, strengthening the protection on time-honored brand $\mathrm{ICH}$, and formulating provisional measures for the recognition and management of representative inheritors of national ICH projects. In 2010, the Ministry of Culture built NECPAs, aiming to protect ICH through regional cooperation. In 2011, the Law of the People's Republic of China on ICH was approved. In 2012, the Ministry of Culture issued guidance on strengthening productive protection of ICH. In 2018, NECPAs management measures were formally promulgated, the aim being to strengthen ICH regional overall protection.

\subsection{China's ICH protection challenges}

Against a background of growing globalization, accelerating modernization, and the rapid 
development of a market economy, China's cultural ecology is undergoing tremendous changes and increasing impact is being given to $\mathrm{ICH} .{ }^{1}$ First, some cultural heritage passing on and inheritance depending on oral instruction and rote memory are disappearing, such as various folk arts, techniques, etiquette, festivals, and entertainment. Second, the survival and development of time-honored brands are facing enormous challenges: some time-honored enterprises have weak awareness of intellectual property protection and pay insufficient attention to the protection of inheritors and traditional skills, and the precious traditional skills and management concepts cannot be inherited effectively. Third, in areas inhabited by ethnic minorities with relatively rich cultural relics, the national or regional cultural features are fading away because of the changes in people's living environments and conditions. There are also other challenges, such as (1) the inheritance of national folk culture is scarce, (2) some traditional skills are on the verge of extinction, (3) a legal system for protecting ethnic and folk cultures is yet to be established, (4) popular awareness of protection is weak, (5) a large number of precious objects and materials of historical and cultural value have been destroyed or lost, and (5) the arbitrary abuse and over-exploitation of ICH occurs from time to time.

\subsection{China attaches great importance to regional overall ICH protection}

In December 2005, the State Council promulgated a law on strengthening ICH protection and made a clear request for regional overall protection in those areas that have rich cultural heritage with relative complete traditional eco-cultural resources. In 2007, the 11th Five-Year Plan (2006-2010) for the cultural development of China specified that traditional culture should be given to regional overall protection. The Ministry of Culture officially established the first NECPEA, namely, the Experimental Eco-cultural Protection Area in southern Fujian Province. The work of building NECPEA had been formally carried out in China. From then on, the Ministry of Culture successively approved 21 NECPEAs involving 17 provincial-level regions. At the same time, 146 provincial eco-cultural protection areas were established with reference to the ideas and practices of NECPEAs. In 2010, the "Guidance Opinion on the Construction of National Experimental Eco-cultural Protection Areas" was published, specifying the significance, guidelines, principles, conditions, procedures, and basic measures, among others, for NECPEA construction. In 2011, the "Notice on Strengthening the Overall Planning of National Eco-cultural Protection Areas" was published, stating that each NECPA should have an overall plan to guide the construction work. In the same year, the "Law of the People's Republic of China on ICH" was formally promulgated and implemented. In Article 26, clear requirements are put forward for the regional overall protection of ICH. From 2011 to 2015, $151 \mathrm{ICH}$ Comprehensive Interpretation Centers were built in 10 NECPAs through financial support of the central government. In 2016, a large number of ICH institutes and traditional craft workstations were built in NECPAs. In 2017, third-party evaluation was introduced for NECPA construction. In recent years, much attention has been paid to the work of NECPA construction. The intention of seeing people, things, and life constitutes the core of NECPA construction.

\footnotetext{
${ }^{1}$ Opinions on Implementing the Project of Inheritance and Development of Chinese Excellent Traditional Culture (2017), Measures for the Management of National Eco-Cultural Protected Areas (2018).
} 


\section{Xiangxi Pilot Zone and the evolution of ICH protection process}

\subsection{Background of the Xiangxi Pilot Zone}

The Tujia and Miao eco-cultural protection experimental area of the Wuling mountain area (Western Hunan), also known as Xiangxi Pilot Zone, is located in the central hinterland of the Wuling mountain area bordering four provincial-level regions (Hunan, Hubei, Chongqing, and Guizhou). Established in May 2010 with the approval of the Ministry of Culture, it is the fifth NECPEA in China and the first to be established in Hunan. The total area of the protection zone is $15,500 \mathrm{~km}^{2}$, covering the entire seven counties and the Xiangxi Tujia and Miao Autonomous Prefecture, with a total population of 2.96 million. The key protection objects are the world cultural heritage of Yongshun Laosi city, the famous historical and

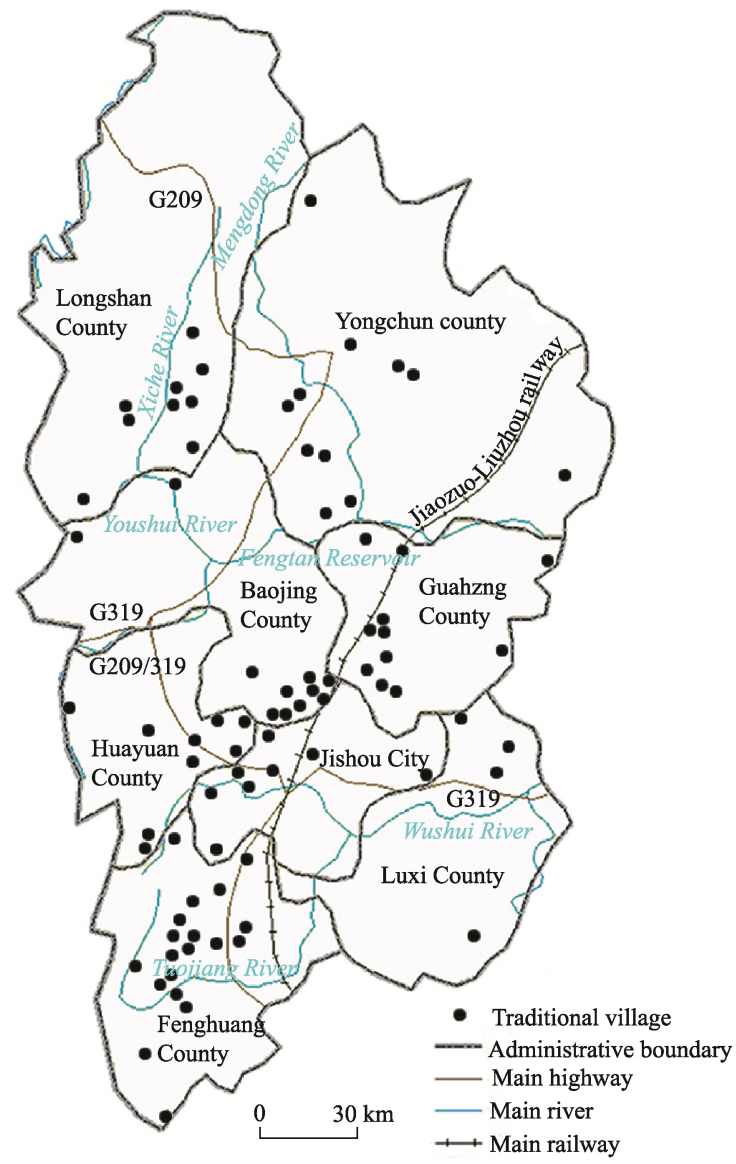

Figure 3 Spatial distribution of Chinese traditional villages in Xiangxi torical and cultural cities of Fenghuang ancient city, and the famous historical and cultural towns of Liye, Wangcun, Chadong, and Pushi, and 82 Chinese traditional villages (Figure 3 ) in the prefecture, 1517 historical and cultural sites of all types, 13 national key cultural relics protection units, 26 national $\mathrm{ICH}$ protection directory projects, 351 cultural relics protection units at all levels, $1056 \mathrm{ICHs}$, 10 national inheritors, and 46 protection areas of various levels and types, with a total area of 289.95 thousand $\mathrm{km}^{2}$. In 2015-2019, Xiangxi invested more than 480 million yuan for ICH protection, and built one prefecture-level traditional technology workstation, one national-level production protection base, two participating institutions of China's research and training program for $\mathrm{ICH}$ inheritor, 10 poverty alleviation workshops on $\mathrm{ICH}$, $62 \mathrm{ICH}$ learning centers (institutes) at all levels, and 1567 village-level cultural service centers (Source: http://whhlyt.

hunan.gov.cn/whhlyt/news/gzdt/201912/ t20191202_10783079.html).

\subsection{Recent evolution of the ICH protection process}

At the beginning of the 21st century, the Xiangxi Prefecture and the Cultural Department of Hunan Province actively declared the Tujia and Miao eco-cultural protection experimental area of the Wuling mountain area (Western Hunan) and have done much work for the inheritance and protection of Xiangxi regional culture. In 2004, the Xiangxi Prefecture was 
integrally listed as a pilot area for the "National Ethnic and Folk Culture Protection Project." In May 2006, the Standing Committee of the People's Congress (PCSC) of the Xiangxi Tujia and Miao Autonomous Prefecture deliberated and passed the "Regulations on the Protection of the National Folk Cultural Heritage of Xiangxi Tujia and Miao Autonomous Prefecture", which is the first prefecture-level local protection law in China. On the basis of this regulation, the Xiangxi Prefecture has issued the "Interim Measures for the Protection and Management of the National Folk Cultural Heritage Inheritors in Xiangxi Autonomous Prefecture". In view of the good eco-cultural environment of the Tujia and Miao nationalities in Xiangxi, especially the abundant ICH resources and good inheritance, the Tujia and Miao eco-cultural protection experimental area of the Wuling mountain area (Western Hunan) was officially set up in 2010 .

\subsection{Main official documents related to ICH protection since 2006}

Since 2006, the Xiangxi Autonomous Prefecture has successively issued a number of local documents, such as the "Regulations on the Protection of the National Folk Cultural Heritage of Xiangxi Tujia and Miao Autonomous Prefecture," "Opinions on Xiangxi's Comprehensive Pilot Work of the Protection Project of Chinese National Folk Culture," "Interim Measures for the Protection and Management of the National Folk ICH in Xiangxi Autonomous Prefecture," "Regulations on Tujia Medicine and Miao Medicine in Xiangxi Tujia and Miao Autonomous Prefecture," and "Notice of the Office of Xiangxi Tujia and Miao Autonomous Prefecture on Establishing the Living Inheritance Mechanism of ICH," constantly increasing efforts to explore the protection of ICH.

In 2006, the "Regulations on the Protection of the National Folk Cultural Heritage of Xiangxi Tujia and Miao Autonomous Prefecture" stipulated integrating the protection of national folk cultural heritage into national economic and social development planning and delimiting the national folk native eco-cultural protection area. In 2018, the "Notice of the Office of Xiangxi Tujia and Miao Autonomous Prefecture on Establishing the Living Inheritance Mechanism of ICH" further emphasized the establishment of a living inheritance mechanism for ICH with the inheritors at its core and further strengthened the construction of the eco-cultural protection area construction system.

\section{Xiangxi practice}

In the process of $\mathrm{ICH}$ protection, relying on the construction of an eco-cultural protection experimental area, according to the policies of China's ICH protection in Table 1, Xiangxi has formed a set of regional overall characteristic ICH protection practice, which comprises (1) constructing an ICH learning system, (2) overall protection based on traditional villages, (3) combining salvageable preservation with productive protection, (4) regional eco-culture and tourism integrated development, and (5) building regional overall characteristic theme parks.

\subsection{Constructing ICH learning system}

In the national eco-cultural protection area, according to the local conditions, comprehensive ICH exhibition sites should be built, and special museums need to be constructed. Furthermore, according to people's needs for study and heritance, representative project of learning 
institutes or sites of ICH at all levels should be established. At the same time, relevant systems and regulations to create conditions and provide support for the representative inheritors of ICH at all levels need to be formulated, aiming to help them to carry out activities of teaching, learning and exchange.

Taking the ICH Museum of the Xiangxi Autonomous Prefecture as the leader, the county-level ICH comprehensive learning center as the backbone, and the township and village learning institute as the basis, the four-level ICH learning base system covering both urban and rural areas was constructed (Figure 4). On this basis, creatively opening master studios, many ICH inheritors have set up professional teams. At present, there are more than 60 training bases, centers, and institutes of various levels and types in Xiangxi, and more than 2000 person-times of trainings have been carried out. The studio works of Tujia brocade project national inheritor Ye Shuiyun, Tread tiger and chisel flowers project provincial inheritor Yang Guijun, and Miao painting project provincial inheritor Liang Songde, among others, are sought after by major museums and art schools. In 2016, the annual subsidy funds of the national, provincial, and prefecture inheritors had increased to 48,000 yuan, 24,000 yuan, and 12,000 yuan, respectively. As of 2018, in Xiangxi there had been one national ICH productive protection base and 12 prefecture-level ICH productive protection bases, 33 national-level, 93 provincial-level, and 392 prefecture-level representative inheritors, and more than 3000 cultural enterprises of various types. More than 60,000 employees have achieved a cultural industrial output value of 3.513 billion yuan (Huang and Chen, 2018).

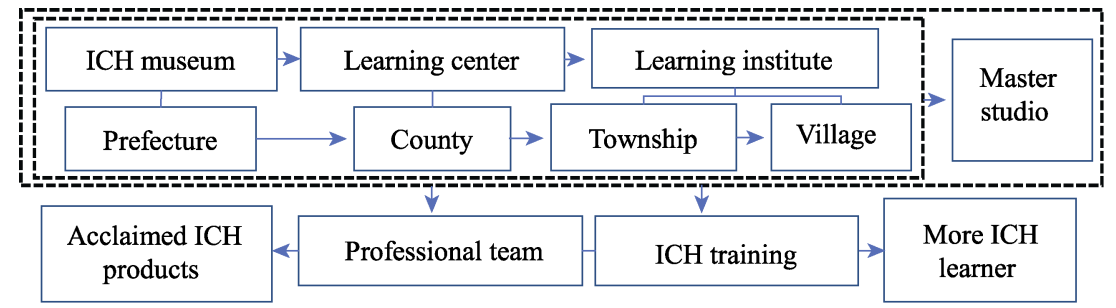

Figure 4 Framework for constructing ICH learning system

\subsection{Overall protection based on traditional villages}

In the eco-cultural protection area, key areas should be identified for overall protection. The streets, communities, towns and villages, whose natural eco-environment is basically good with relative complete traditional eco-cultural resources, should be selected as the key areas for overall protection.

In the eight cities and counties across the prefecture, a village with well-protected natural ecology, cultural ecology, and ICH and rich folk customs and cultural resources has been identified respectively as an overall protection pilot village. According to the actual situation of each pilot village, implementation plans with different characteristics should be worked out. In the pilot villages, emphasis is placed on the national traditional festivals and the site selection and construction for learning institutes and productive protection based on advocating the speaking of national languages, the wearing of national costumes and the learning of national customs, safeguarding the eco-environment of clear waters and green mountains, restoring the survival space of $\mathrm{ICH}$, and exploring examples of $\mathrm{ICH}$ overall protection (Figure 5). Traditional villages such as Rebala and Shuangfeng are among the pilot villages. 


\begin{tabular}{|c|c|c|c|}
\hline $\begin{array}{c}\text { Eco-environment } \\
\text { construction }\end{array}$ & $\begin{array}{c}\text { ICH } \\
\text { protection }\end{array}$ & $\begin{array}{c}\text { Traditional village } \\
\text { protection }\end{array}$ & $\begin{array}{c}\text { Eco-cultural improvement } \\
\text { of the entire village }\end{array}$ \\
\hline $\begin{array}{c}\text { Service center } \\
\text { construction }\end{array}$ & $\begin{array}{c}\text { Restoration and renovation of } \\
\text { dwellings with ethnic characteristics }\end{array}$ & $\begin{array}{c}\text { Eco-landscape } \\
\text { construction }\end{array}$ \\
\hline $\begin{array}{c}\text { Construction of } \\
\text { productive protection base }\end{array}$ & $\begin{array}{c}\text { Eco-cultural display } \\
\text { and education }\end{array}$ & \begin{tabular}{|c|c|} 
Study \\
activities, etc.
\end{tabular} \\
\cline { 1 - 2 }
\end{tabular}

Figure 5 Framework for overall protection based on traditional villages

\subsection{Combined salvageable preservation with productive protection}

Construction of national eco-cultural protection area should fully respect the dominant position of people. The policy on "protection and rescue first, rational utilization, inheritance and development" of ICH should be implemented. Adhering to the principle of giving priority to protection, living inheritance and protection-based development, keeping pace with the times on the basis of maintaining existing characteristics, and creating the content and form that integrates with reality, should be encouraged, in the construction of national eco-cultural protection area.

With the organic combination of rescue protection and productive protection, the ICH digital protection center has been established (Figure 6). At present, the digital protection of national projects such as Miao drum dance, Tujia brocade skills, Fenghuang paper artwork, Youshui boatmen's chant, and Tujia Kukiahe has been fully completed. There is now one national ICH productive protection base and 12 state-level ICH productive protection bases in the protection area. With the implementation of the traditional craft revitalization plan as an opportunity, focusing on supporting the upgrading of Tujia brocade skills, Miao silver forging techniques, and Miao embroidery ICH products in Xiangxi, a number of ICH productive protection leading enterprises have been created, and the Xiangxi traditional craft workstation has been jointly established with the well-known domestic clothing brand MOZEN. From 2014 to 2018, Xiangxi received a total of 60.51 million yuan as special funds for cultural and ecological protection areas, more than 14 million yuan for the construction of production protection bases for state-level non-legacy projects, and 3.02 million yuan for non-legacy projects. Besides, the annual budget of the state provides 1.3 million yuan as special funds for the special protection of the legacy, and the budgets of counties and cities arrange about 200,000 yuan as special funds for the protection of the legacy each year (Huang and Chen, 2018).

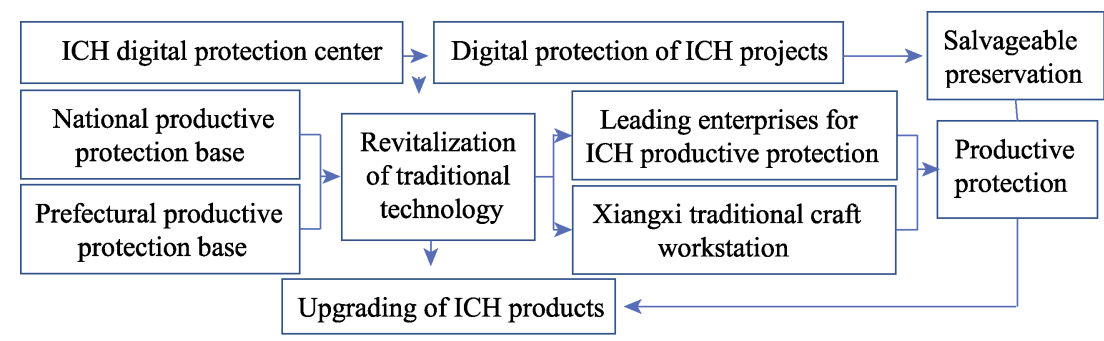

Figure 6 Framework for combined salvageable preservation and productive protection 


\subsection{Regional eco-culture and tourism integration}

The construction and management institutions of national eco-cultural protection areas should not only encourage and support the locals to hold traditional cultural activities in accordance with local customs and regulations, but also carry out various forms of tourism activities such as cultural sightseeing tour, cultural experience tour and cultural leisure tour, relying on the unique cultural and ecological resources.

Based on regional proximity, cultural similarity, and resource complementarity, with the aim of building an internationally renowned eco-cultural tourism destination, a cultural diversity and ecological diversity protection demonstration zone, and creating the Xiangxi eco-cultural brand, the Xiangxi Autonomous Prefecture should firstly strengthen the protection and development of the eco-landscape, historical culture, religious culture, red culture, and folk culture of Xiangxi. Secondly, based on the projects of international eco-cultural tourism and leisure resort, economic and industrial belt, eco-cultural industrial park, infrastructure, eco-cultural landmark, efforts should be made to strengthen regional integrated development of heritage tourism, rural tourism, ancient city and village tourism and other sightseeing experiences, leisure and holiday, and new business products. Therefore, some top-quality tourist routes, such as mysterious Xiangxi, heritage Xiangxi, ecological Xiangxi, creative Xiangxi, red Xiangxi, scientific research Xiangxi, exploring Xiangxi, and slowly living Xiangxi can be forged. Finally, a comprehensive security support system can be perfected in transportation network, tourism distribution network, service system, industrial integration, ecological environmental protection and construction, cultural protection and development and utilization, and institutional mechanisms.

At the same time, by taking national traditional festivals as an important carrier of eco-cultural protection, a comprehensive investigation of the national traditional festivals of the whole prefecture was carried out, and more than 100 traditional festivals were divided into four categories, namely (1) national traditional festivals, (2) traditional folk activities, (3) traditional national sacrifices, and (4) cultural tourism festivals, with 29 basic and conditional national traditional festivals being chosen for support. In the national traditional festival activities, the principle that should adhere to is to let the masses be the protagonists, compiling and performing various types of programs by themselves (Figure 7). From 2014 to 2017, more than 100 various types of national festivals have been held involving more than 400,000 people in the Xiangxi Tujia and Miao autonomous prefecture, which are actively developing all kinds of cultural tourism industries so as to promote the protection of $\mathrm{ICH}$.

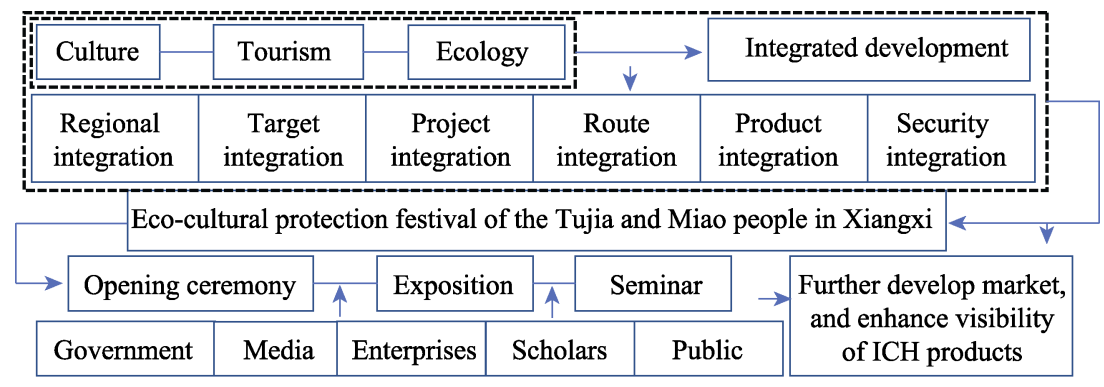

Figure 7 Framework for regional eco-culture and tourism integrated development 


\subsection{Building regional overall characteristic theme parks}

In the construction of national eco-cultural protection area, keeping pace with the times on the basis of maintaining the existing characteristics, and creating the content and form that integrates with the reality, are encouraged. Based on the advantages of local eco-culture and combined with the development of comprehensive tourism, building regional overall characteristic theme parks is a pioneering work of Xiangxi. Xiangxi is projected to be constructed and managed as a large park as a whole in terms of ecology, culture, tourism, and health and preservation.

The "Development Plan for the Eco-cultural Park of Xiangxi Tujia and Miao Autonomous Prefecture" was formulated (Figure 8). It is derived from the ecological and cultural advantages of Xiangxi and is planned to turn the $15,000 \mathrm{~km}^{2}$ of territorial land into a regional park. At the same time, many characteristic theme parks have been constructed. The Xiangxi farming culture eco-tourism experience park project is located in Guzhang County of Xiangxi Prefecture. It integrates the original ecological tourism resources with the unique historical and cultural resources of Xiangxi and the abundant farming culture resources in Guzhang. It takes tea gardens as its theme, with farming culture as the main line and agricultural tourism, leisure health, local products, farming, folk culture, and ecological environment as the economic chain. The main contents include farming culture display and experience, local recreation, modern agricultural display, special diet tasting, and tourism service infrastructure and leisure landscape. The "Xiangxi square" pioneer park, aiming at the win-win situation of cultural ecology and tourism industry, is located in the ancient city of Qianzhou in Jishou City. It focuses on the development of national cultural industries, speciality commodity industries, local food and beverage industries, and leisure and entertainment industries, and it gathers classic cultures of Xiangxi, ethnic speciality goods, and master craftsmen. It supports the national ecological economic construction in Xiangxi, and inherits the $\mathrm{ICH}$, and contributes to the eco-cultural tourism industry, thereby achieving a win-win situation.

\begin{tabular}{|c|c|c|c|}
\hline $\begin{array}{c}\text { Eco-cultural } \\
\text { resources endowment }\end{array}$ & $\begin{array}{c}\text { Geographical } \\
\text { location conditions }\end{array}$ & $\begin{array}{c}\text { Infrastructure } \\
\text { support }\end{array}$ & $\begin{array}{c}\text { Social and } \\
\text { economic support }\end{array}$ \\
\hline $\begin{array}{c}\text { Guzhang county } \\
\text { Farming culture ecotourism experience garden in Xiangxi }\end{array}$ & Regional overall characteristic theme parks & $\begin{array}{c}\downarrow \\
\text { Qianzhou ancient city }\end{array}$ \\
\hline
\end{tabular}

Figure 8 Framework for building regional overall characteristic theme parks

\section{Discussion}

Located in the central part of China, Xiangxi Prefecture is the hinterland of the Wuling mountain area and the junction of Hunan, Hubei, Chongqing, and Guizhou. With rich cultural and ecological resources, it is an important region for China's eco-cultural protection and development. At present, the mountainous area of Xiangxi Prefecture accounts for $70 \%$ of the total area, and its eco-cultural tourism industry is developing well. Well-known tourism sectors in areas such as Fenghuang, Jishou, Hibiscus Town, and Liye have been formed 
initially. As the first NECPEA in the pilot areas of national western development, (Wuling mountain district) regional development, and poverty alleviation, Xiangxi has further proved its strategic position in the eco-cultural protection of China. Thus, the Xiangxi model should be summarized and used for reference to other less-developed areas in central China like western Hunan especially mountainous areas that have similar ICH features and eco-cultural development conditions to those of Xiangxi. As elaborated in the Xiangxi model, it can be repeated and widely introduced in terms of policies and practices such as the protection of eco-cultural resources, the inheritance of $\mathrm{ICH}$, the construction of the environment, and regional cooperation.

It is worth noting that there are hidden dangers in the construction of the Xiangxi eco-cultural protection area that directly affect the regional overall protection of ICH. The insufficient protection ability and consciousness of some local residents is not particular to Xiangxi but rather is a common situation in China (Rees, 2018; Chen et al., 2019; Xu and Pan, 2019). Local residents are important participants in the construction of eco-cultural protection areas, and it is very important to understand their ability and consciousness to protect ICH. An in-depth study of this phenomenon may be related to changes in the production and lifestyle of rural residents.

Since the end of the 20th century, China has witnessed rapid urbanization. The proportion of urban population to the total population increased from $33.35 \%$ in 1998 to $58.52 \%$ in 2017 (Figure 9), the rural population flew out in large numbers, resulting in a drop of rural population from 831.53 million in 1998 to 576.61 million in 2017 (Figure 9). The urbanization has promoted the progress of society, but it also exerted a certain impact on rural development, leading to a series of problems related with "hollowing village" (Bai et al., 2014; Liu et al., 2016). The elderly, children, and other vulnerable groups in the left-behind villages lack the ability to effectively protect eco-cultural resources. At the same time, because of the increase in the income of migrant workers in cities coupled with the expansion of family size, the ability and demand of young adults to build new homes in rural areas has been increasing, which has caused great damage to the traditional eco-cultural resources of villages (Demotte, 2004; Long et al., 2016; Liu and $\mathrm{Li}, 2017$ ).

It is noteworthy that the key to the construction of NECPAs is meeting people's needs.
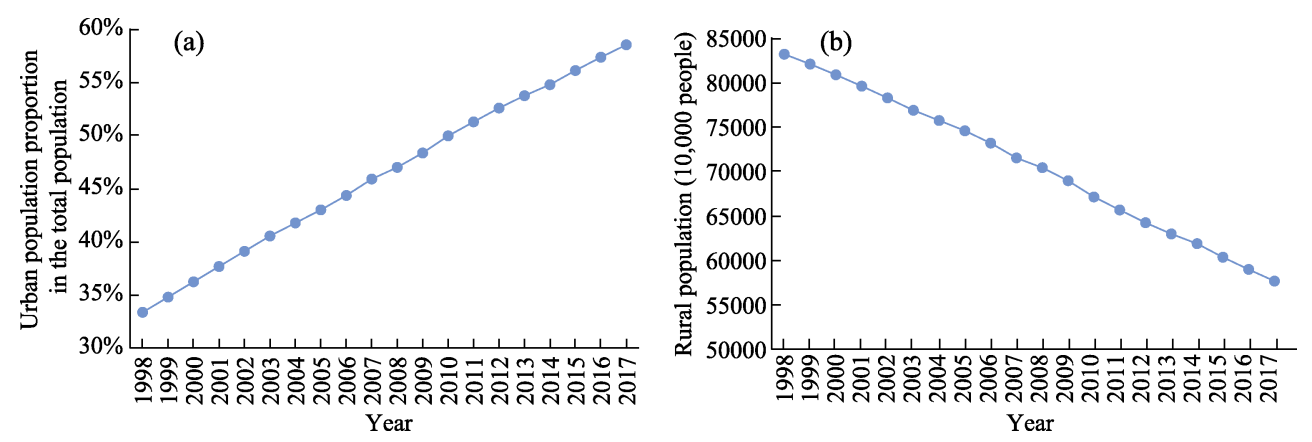

Figure 9 Crucial indicators of urban and rural population in China (Source: http://tongji.cnki.net/kns55/Dig/dig.aspx) 
In 2008, the number of visitors to the antiquities industry was 354.36 million person-times in China, and in 2017 it increased to 117.773 million person-times, with an average annual growth rate of over $20 \%$ (Figure 10). The number of practitioners in the antiquities industry in 2008 was 92,060 and increased to 161,577 in 2017, with an average annual growth rate of nearly $10 \%$ (Figure 10). Therefore, it is necessary to be people-oriented and allow local residents to become the main participants in the construction of eco-cultural protection areas and the protection of $\mathrm{ICH}$. However, in practice, the local residents' lack of protection ability and weak sense of participation have hindered the construction of eco-cultural protection areas and deviated from the dream of regional overall protection of $\mathrm{ICH}$.
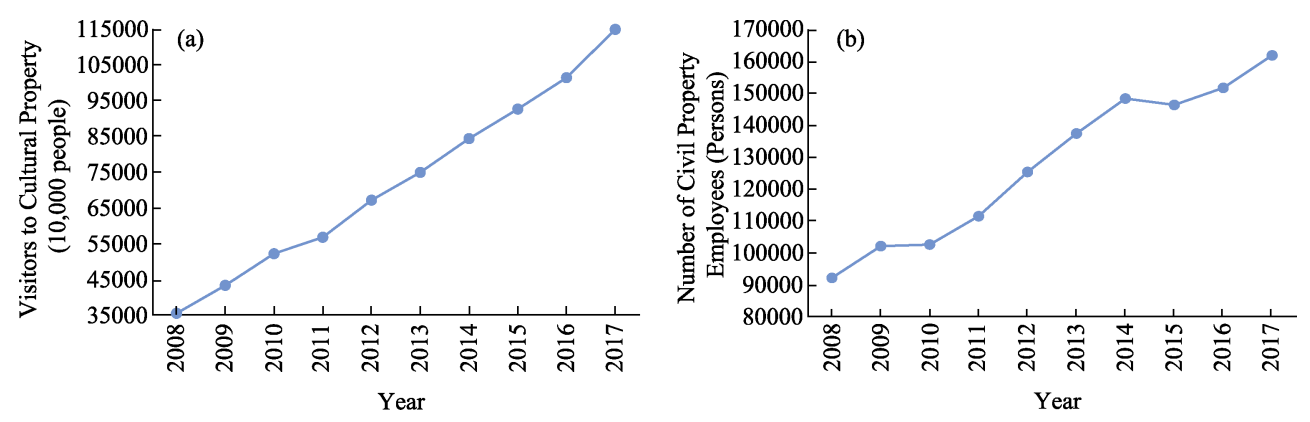

Figure 10 Crucial indicators of people's needs for cultural property in China (Source: http://tongji.cnki.net/kns55/Dig/dig.aspx)

In this context, on the one hand people's demand for eco-culture is growing, the number of eco-cultural practitioners is increasing, and the development momentum for eco-cultural tourism is gratifying. On the other hand, the development of urbanization leads to a large outflow of rural population, and the rural labor force is decreasing. At the same time, the impact of modern development on traditional eco-cultural resources is increasing day by day, and the squeeze of rural modern facilities on traditional eco-cultural environment space is becoming more and more obvious. All these problems have brought challenges to the eco-cultural management departments.

Besides, poor awareness of the historical environment also hinders the protection of $\mathrm{ICH}$. The historical environmental protection consciousness of the local residents is too poor, which hinders the regional overall protection of $\mathrm{ICH}$ in China, especially in the following aspects: (1) awareness is not in place, not aware of the true value of $\mathrm{ICH}$, laissez-faire damage and destruction; (2) lack of responsibility, even if there is a certain understanding of the value, but because it cannot produce immediate economic benefits, showing indifference; and (3) lack of funds, in the face of the obvious destruction and rapid destruction of $\mathrm{ICH}$, showing powerless.

\section{Conclusions}

Compared with the previous ICH protection measures, regional overall $\mathrm{ICH}$ protection fully satisfies the sustainable development requirements of regional cultural ecology and the actual needs of potential residents. In China, from 2008 to 2017, the number of visitors to the 
antiquities industry and the number of practitioners in the antiquities industry both increased, with average annual growth rate of $20 \%$ and $10 \%$ respectively.

Xiangxi had made great progress in regional overall ICH protection, by building the Tujia and Miao eco-cultural protection experimental area of the Wuling mountain area (Western Hunan), constructing an ICH learning system, overall protection based on traditional villages, combining salvageable preservation and productive protection, regional eco-culture and tourism integrated development, and building regional overall characteristic theme parks. More than 60,000 employees achieved a cultural industrial output value of 3.513 billion yuan in 2016, and more than 100 various types of national festivals were held involving more than 400,000 people from 2014 to 2017.

From the Xiangxi practice of building national eco-cultural protection areas, the following general reference value can be summarized for the development of $\mathrm{ICH}$ in other parts of China. On the one hand, the development of local ICH should be organically combined with the relevant policies on the overall development of the national $\mathrm{ICH}$, and advanced in the overall development process of the national $\mathrm{ICH}$, so as to refine and implement the national ICH policies. For example, determining the key areas for overall protection, strengthening the protection of the representative inheritors of the ICH list projects, scientifically formulating the overall plan of the eco-cultural protection area, encouraging the exploration of productive protection methods, giving priority to the rescue of the endangered ICH list projects in the protection area, and highlighting the cultural subject status of the public, are the basic requirements for the overall development of the national $\mathrm{ICH}$. On the other hand, it is necessary to carry out certain innovations, in accordance with the characteristics of local eco-cultural resources and the actual situation of socio-economic development. For example, combined with the background of comprehensive tourism development policy, Xiangxi established eco-cultural parks, and obtained good eco-cultural benefits and socio-economic values.

The goal of regional overall ICH protection is to be responsible for cultural forms with rich historical and cultural heritages, good survival status, important values, and distinct characteristics, and to abide by the laws of nature. In response, the Chinese government proposes to build NECPAs and has made great progress, but we are also faced with the challenge of insufficient protection capacity and awareness among some local residents. To have a more comprehensive understanding of the construction of NECPAs and the regional overall $\mathrm{ICH}$ protection, other aspects of the research should also be carried out. At the same time, the construction of NECPAs and the regional overall ICH protection is a multi-faceted strategy to be implemented in the long term. The promulgation of the "National Eco-cultural Protection Areas Management Measures (2018)" and so on is a preliminary stage for policy makers to decompose tasks and check results, and it is also a new development requirement.

Much research still should be conducted to sum up proper developing modes that we can take effective measures to increase the rate of promotion of $\mathrm{ICH}$ protection. The special issues observed in each of the places examined in this study should not be neglected and deserve further research. 


\section{References}

Ahmad Y, 2006. The scope and definitions of heritage: From tangible to intangible. International Journal of Heritage Studies, 12(3): 292-300.

Arizpe L, 2004. Intangible cultural heritage, diversity and coherence. Museum International-Oxford, 56(1): $130-136$.

Arizpe L, 2015. How to reconceptualize intangible cultural heritage. In: Culture, Diversity and Heritage: Major Studies. Springer International Publishing.

Bai X M, Shi P J, Liu Y S, 2014. Realizing China's urban dream. Nature, 509 (1799): 158-160.

Bille M, 2012. Assembling heritage: Investigating the UNESCO proclamation of Bedouin intangible heritage in Jordan. International Journal of Heritage Studies, 18(2): 107-123.

Chen J, Xiao R, Zhang Z L et al., 2019. Protection and development strategy of intangible cultural heritage in Xiangxi based on regional brand. New West, (36): 44-47. (in Chinese)

Chen M X, Gong Y H, Lu D D et al., 2019. Build a people-oriented urbanization: China's new-type urbanization dream and Anhui model. Land Use Policy, 80: 1-9.

Chen M X, Lu D D, Liu W D, 2016. Challenges and the way forward in China's new-type urbanization. Land Use Policy, 55: 334-339.

Chen M X, Ye C, 2014. Differences in pattern and driving forces between urban and rural settlements in the coastal region of Ningbo, China. Sustainability, 6(4): 1848-1867.

Cominelli F, Greffe X, 2012. Intangible cultural heritage: Safeguarding for creativity. City Culture \& Society, 3(4): 245-250.

Cozzani G, Pozzi F, Dagnino F M, 2017. Innovative technologies for intangible cultural heritage education and preservation: The case of i-Treasures. Personal \& Ubiquitous Computing, 21(2): 1-13.

Dans E P, González P A, 2018. The Altamira controversy: Assessing the economic impact of a world heritage site for planning and tourism management. Journal of Cultural Heritage, 30: 180-189.

Del Barrio M J, Devesa M, Herrero L C, 2012. Evaluating intangible cultural heritage: The case of cultural festivals. City, Culture and Society, 3(4): 235-244.

Demotte R, 2004. National policies concerning intangible cultural heritage: The example of Belgium's French community. Museum International, 56(1/2): 174-179.

Elliott M A, Schmutz V, 2012. World heritage: Constructing a universal cultural order. Poetics, 40(3): 256-277.

Giudici E, Melis C, Dessì S, 2013. Is intangible cultural heritage able to promote sustainability in tourism? International Journal of Quality \& Service Sciences, 5(1): 101-114.

Greenwood D, 1989. Culture by the pound: An anthropological perspective on tourism as culture commoditizing. Hosts and Guests: The Anthropology of Tourism, (2): 99-110.

Han J H, Park K B, 2009. A study on preservation of regional inheritances and utilization method based on the concept of eco-museum-focusing on Cheonan. Journal of the Korean Institute of Rural Architecture, 11(1): 67-74.

Harrison X A, Tregenza T O M, Inger R et al., 2010. Cultural inheritance drives site fidelity and migratory connectivity in a long distance migrant. Molecular Ecology, 19(24): 5484-5496.

Huang Q S, Chen H, 2018. Record of the construction of eco-cultural protection area of Xiangxi Tujia and Miao Autonomous Prefecture. Hunan Daily, 12-24. (in Chinese)

Hudečková H, Ševčíková A, 2007. The renewal of the rural cultural heritage of the Czech Republic with the support of regional policy. Agricultural Economics-Czech, 53(11): 505-512.

Liu Y S, Li Y H, 2017. Revitalize the world's countryside. Nature News, 548(7667): 275.

Liu Y S, Long H L, Chen Y F, 2016. Progress of research on urban-rural transformation and rural develop- 
ment in China in the past decade and future prospects. Journal of Geographical Sciences, 26(8): 1117-1132.

Lixinski L, 2013. Intangible Cultural Heritage in International Law. Oxford: Oxford University Press.

Long H L, 2014. Land consolidation: An indispensable way of spatial restructuring in rural China. Journal of Geographical Sciences, 24(2): 211-225.

Long H L, Ge D Z, Zhang Y N et al., 2018. Changing man-land interrelations in China's farming area under urbanization and its implications for food security. Journal of Environmental Management, 209: $440-451$.

Long H L, Tu S S, Ge D Z, 2016. The allocation and management of critical resources in rural China under restructuring: Problems and prospects. Journal of Rural Studies, 47: 392-412.

Long H L, Woods M, 2011. Rural restructuring under globalization in eastern coastal China: What can be learned from Wales? Journal of Rural and Community Development, 6(1): 70-94.

Pan S Y, 2008. Museums and the protection of cultural intangible heritage. Museum International, 60(1/2): $12-19$.

Rees H, 2018. Intangible cultural heritage in contemporary China: The participation of local communities. International Journal of Heritage Studies, 24(5): 570-572.

Smith L, Morgan A, Van der Meer A, 2003. Community-driven research in cultural heritage management: The Waanyi women's history project. International Journal of Heritage Studies, 9(1): 65-80.

Stanik N, Aalders I, Miller D, 2018. Towards an indicator-based assessment of cultural heritage as a cultural ecosystem service: A case study of Scottish landscapes. Ecological Indicators, 95: 288-297.

Tengberg A, Fredholm S, Eliasson I et al., 2012. Cultural ecosystem services provided by landscapes: Assessment of heritage values and identity. Ecosystem Services, 2: 14-26.

Varnum M E, Grossmann I, 2017. Cultural change: The how and the why. Perspectives on Psychological Science, 12(6): 956-972.

$\mathrm{Xu}$ B C, Pan J H, 2019. Analysis of structural characteristics and spatial distribution of the national intangible cultural heritage in China and its policy implications. Sciences in Cold and Arid Regions, 11(5): $389-406$.

Zhou Y, Sun J, Huang Y, 2019. The digital preservation of intangible cultural heritage in China: A survey. Preservation, Digital Technology \& Culture, 48(2): 95-103. 